\title{
INTERNET OF THINGS ENABLED ELECTRONIC MARKETS: TRANSPARENT, COLLABORATIVE, AND AUTOMATED
}

\author{
Bhavik K. Pathak, Indiana University South Bend, bkpathak@iusb.edu
}

\begin{abstract}
The rapid and successful evolution of the electronic markets is enabled by information and communication technology (ICT) tools such as recommender systems, reputation feedback systems, product reviews and ratings, peer-to-peer payment mechanisms, and parametric search functions. In recent years, the Internet of things (IoT) has connected billions of devices around the world to collect and share data on product and process performance, physical surroundings, and usage patterns. These IoT-based smart objects have a profound impact on three core business processes: product lifecycle management (PLM), supply chain management (SCM), and customer relationship management (CRM). Drawing on the theories in the fields of ICT-led electronic markets and IoT applications, this paper shows how IoT can transform the next generation of electronic markets by making them more transparent, collaborative, and automated. The paper contributes to the theory of the electronic markets by showing how the IoT can extend the product life cycle management beyond the firm's boundaries, enable live tracking of the product in upward and downward supply chains, and provide proactive customer relationship management (CRM) services. The challenges faced by electronic markets during such transformation are also discussed.
\end{abstract}

Keywords: Internet of Things, Electronic Commerce, Electronic Markets, IoT, Product Lifecycle Management, Supply Chain Management, Customer Relationship Management

\section{INTRODUCTION}

Electronic markets are networked information systems serving as an enabling infrastructure for sellers and buyers to exchange information, transact, and perform other transactional activities before, during, and after the transaction (Vardarajan \& Yadav, 2002). Electronic markets provide a legal and regulatory framework to facilitate trade transactions between sellers and buyers. They have improved market efficiency by reducing search costs, price dispersion, and information asymmetry. In the last couple of decades, electronic markets have integrated various ICT tools to improve the major challenges, such as trust deficiency. These ICT tools include personalization, parametric search, product reviews and star ratings, and reputation feedback mechanism.

The emergence of the Internet of things (IoT) has created a network of Internet-connected devices. These connected devices or smart objects have a profound impact on various business processes. The primary objective of this paper is to study the contemporary research in the field of IoT and business to determine the effect of the IoT on the core business processes and how such impact will transform the electronic markets. Based on the study of the literature and current developments, this research shows that IoT-enabled organizations can extend the product life cycle management beyond the firm's boundaries, enable live tracking of the product in upward and downward supply chains, and provide proactive customer relationship management (CRM) services. The paper further studies the impact of IoT in the context of electronic markets and concludes that the IoT-enabled electronic markets will become more transparent, collaborative, and automated. The rest of the paper is organized as follows. The next section summarizes the key theoretical developments in the evolution of electronic markets. This is followed by a literature review section on the emergence of the IoT and how it impacts the core business processes. This research's core contribution, IoTled transformation of the electronic markets, and the challenges in the effective transformation of the electronic markets are summarized in the next sections.

\section{EVOLUTION OF ELECTRONIC MARKETS}

The electronic markets should perform three essential functions: enabling the matching of participants (e.g., sellers and buyers), facilitating the transaction of information, goods, services, and payments, and providing the legal and regulatory framework (Bakos, 1992). Before the advent of the Internet, the role of electronic markets was primarily 


\section{Issues in Information Systems \\ Volume 21, Issue 4, pp. 306-316, 2020}

limited to transactions within a firm's supply chain or business-to-business (B2B) exchanges. Malone, Yates, \& Benjamin (1987) discuss how computerized integrated information systems supported by the database, EDI, and networking technologies, have increased the number of B2B transactions and revolutionized the electronic transactional reservation systems in financial markets and airline reservations. The emergence of the Internet has taken electronic markets beyond the internal value chain of the firm and enabled both the business to consumer (B2C) and consumer to consumer (C2C) exchanges. The popular B2C and C2C markets, including Amazon, eBay, eHarmony, eLance, Craigslist, Etsy, and the Facebook marketplace, have integrated various Internet-enabled technologies to perform the three essential electronic market functions of matching of participants, enabling transactions, and providing the regulatory framework.

\section{Impact of Electronic Markets on Market Efficiency}

Prior researchers have discussed the impact of electronic markets on search costs, price dispersion, information asymmetry, and market efficiency. In a typical market, buyers have to incur significant costs to acquire information about seller prices and product characteristics (Bakos, 1997). The ICT tools on the Internet, including parametric search, multimedia product demonstration, and comparison shopping agents, have been instrumental in making search costs negligible. In electronic markets, buyers can compare more product offerings, which may lead to competition among sellers and ultimately reduced prices (Bakos, 1991). The information search cost theory suggests that as long as there is a marginal cost for acquiring product and price information, retailers may charge differential prices, which will result in price dispersion in markets. Price dispersion should not be existent in electronic markets given the negligible search costs in these exchanges. In the traditional markets, information asymmetry between sellers and buyers can also result in price dispersion. Brynjolfsson \& Smith (2000) discuss that electronic markets reduce information asymmetry. This aspect of electronic markets is known as frictionless commerce. Although electronic markets reduce search costs and information asymmetry substantially, their impact on market efficiency is not conclusive. It has been shown that price dispersion still exists in electronic markets because of the seller and buyer heterogeneities (Baye, Morgan, \& Scholten, 2006; Chen \& Hitt, 2002; Clay, Krishnan \& Wolf, 2001; Smith \& Brynjolfsson, 2001; Resnick \& Zeckhauser, 2002). Soh, Marcus, \& Goh (2006) discuss that higher price transparency and lower prices in electronic markets may discourage sellers' participation. They further suggest that electronic markets should offer compensatory benefits to sellers or buyers to offset higher or lower transparency and attract their participation.

While the reduction of search costs, price dispersion, and information asymmetry have made electronic markets more efficient, their intrinsic characteristics have created some challenges as well. Although electronic markets provide more information to participants, Ackoff (1967) pointed out the dark side of information. Grover, Lim, \& Ayyagari (2006) studied the information overload and information equivocality as the dark sides of information and showed how they affected price dispersion.

The existence of network effects in the markets is well discussed in the literature. Successful electronic markets such as eBay and Amazon have shown that the first mover can create quite effective entry barriers by building a sizable community of participants. On the one hand, having an extensive network of users increases the value proposition of electronic markets because of the network externality (Bakos 1991, 1997). On the other hand, it also increases the number of available alternatives and correspondingly the cognitive burden on the participants, effectively reducing their decision effectiveness (Grover, Lim, \& Ayyagari, 2006; Hiltz \& Turoff, 1985; Keller \& Staelin, 1987; Lee \& Lee, 2004; Malhotra, 1982; Pontiggia \& Fancesco 2010). Lee \& Mason (2001) also discuss that markets with large communities tend to have negative network externalities because of the increased consumption, congestion, and slow access to the firm's resources. Trust deficiency is also a significant issue faced by electronic markets. Most of the transactions in electronic markets happen between participants who may not have met before. In many instances, sellers may not provide complete and accurate information, and such incomplete information and asymmetry create trust deficiency in the markets (Swan \& Nolan 1985). The seller trustworthiness can also be diminished if the buyer is lenient in providing feedback about the sales transaction (Bolton, Kusterer, \& Manns, 2019). 


\section{Issues in Information Systems}

Volume 21, Issue 4, pp. 306-316, 2020

\section{Integration of ICT Tools}

Electronic markets have integrated a range of ICT tools to address these challenges. Such integration has also helped electronic markets to perform three primary functions of matching of buyers and sellers, facilitating transactions, and providing regulatory framework more efficiently.

Matching buyers and sellers: Electronic markets use advances in database technologies and data analytics to minimize the search costs associated with finding the product, price, or participant match. The ICT tools, including product reviews and star ratings, have been instrumental in reducing product-related uncertainties. The advances in the big data have made it possible to conduct analytics at the individual level and offer cost-effective personalization to participants. Such personalization not only enhances the user experience but also reduces the product, price, and trading participant related search costs. In the context of online retailers, Pathak, Garfinkel, Gopal, Venkatesan, \& Yin (2010) show that the ICT-enabled personalization technologies such as recommender systems tend to reduce the information overload on the buyers and increase the sales of the products. Thus, the ICT tools such as parametric search, product reviews and star ratings, recommender systems, and personalization have helped buyers in identifying products or sellers and thereby enabling matching of the sellers and buyers.

Facilitating transactions: Scholars have also studied how ICT tools such as reputation feedback systems and payment mechanisms have helped in overcoming the challenges posed by the trust deficiency in electronic markets. Electronic markets have effectively integrated reputation feedback system-based applications wherein the participating sellers and buyers can rate each other on various dimensions, including communication, the accuracy of the product listing, timely delivery, and payments. Reputation feedback systems have reduced the risks and uncertainties associated with the adoption of electronic markets (Ba \& Pavlou 2002). The role of the third party escrow services and credit card guarantees has also been studied in the context of settlement of payments and facilitating transactions. Pavlou \& Grefen (2004) show that to engender trust in electronic markets, both the market-driven weak-mechanism (e.g., reputation feedback system) and legally binding robust mechanisms (e.g., credit card guarantees, Amazon.com's Ato-Z Guarantee Protection and eBay buyer protection's money-back guarantee) are necessary. The integration of these features has facilitated efficient transactions between buyers and sellers.

Providing institutional infrastructure: Electronic markets offer a regulatory framework to report any breach of contract, listings violating intellectual property rights, and selling of counterfeit items. Apart from these user-initiated reports, electronic markets also closely monitor user ratings on the reputation feedback systems. For example, on Amazon's marketplace, multiple negative feedbacks on the reputation feedback system can result in the closing of the seller's account (Danziger, 2018). In the context of the gig economy, Benson, Sojourner, and Umyarov (2020) provide evidence that the reputation feedback mechanisms can play a vital role in the labor market in terms of attracting qualified employees to employers.

Implementation of these ICT features has helped in addressing some of the challenges associated with online shopping through electronic markets. The technological evolution of ICTs has advanced into the development of new platforms, including blockchain and IoT. Contemporary research has shown that such advancements can significantly affect the value proposition of the electronic markets by increasing the transparency of information between sellers and buyers (Bauer, Liudmila, \& Gerhard, 2019)

\section{THE EMERGENCE OF IOT AND ITS IMPACT ON BUSINESS}

During their evolution in the last couple of decades, electronic markets have been integrating various ICT features to continuously improve the matching of participants, facilitating transactions, and providing a regulatory framework. Traditionally, ICTs are defined as computers, software, and telecommunications technologies that capture, store, process, transmit and retrieve information (Lyytinen \& King, 2006; Hanna, 2003). In recent years, the Internet of things (IoT) has emerged as a converging technology platform that can extend the reach of ICTs beyond traditional computing boundaries by connecting potentially every single device in the world. Such IoT-enabled devices are called 'smart objects.' IoT will have a direct impact on three of the major business processes: Product Lifecycle Management (PLM), Supply Chain Management (SCM), and Customer Relationship Management (CRM) 


\section{IoT and Extended Product Lifecycle Management}

The characteristics of the smart objects include integrated computing power (pervasive computing), always connected (ubiquitous communication), and active physical environment monitoring (ambient intelligence) (Dohr, 2010). The number of smart objects is expected to grow to 80 billion in 2025, and they will generate 180 zettabytes of data by 2025 (Kanellos, 2016). The ubiquitously connected computer-enabled devices can use ambient intelligence to monitor the surrounding physical environment. Based on the application domain, these smart objects can monitor the activity or events and can even implement the predefined rules. Manufacturers can track their products (i.e., smart objects) throughout the entire lifecycle, from production to disposal (Bandopadhyay \& Sen, 2011). Traditionally, the product lifecycle management process starts from product inception to the disposal of the manufactured item. The IoT extends the product lifecycle management process beyond the firm's boundaries. IoT-enabled firms can track raw materials and finished products in their upward and downward supply chains, monitor the performance of their products in consumer households, and can also take proactive corrective actions before the product malfunctions.

\section{IoT Ecosystem and Supply Chain Management}

Scholars have studied the IoT in the context of ecosystems and suggested that current business model frameworks are inadequate in analyzing the IoT-based businesses as they focus on the challenges faced by a single firm (Weiller \& Neely, 2013). Moore (1993) introduced the ecosystem concept where firms from multiple industries are interdependent for their survival and growth. In the business ecosystem, firms can be independent and interdependent and can compete and collaborate at the same time. Tarkoma \& Katasonov (2011) and Westerlund, Leminen, \& Rajahonka (2014) discuss that the IoT-business models consist of companies connected by product-based linkages. Leminen, Rajahonka, Westerlund, \& Wendelin (2018) emphasize that the emerging IoT business models will not be limited to a single industry; instead, they span over multiple sectors. They envisioned four IOT-based ecosystem models. The value-chain business models focus on improving the efficiency of a firm and its supply chain. Two other models are more open and integrate other firms in the vertical and horizontal markets, respectively. The fourth model is a platform-based model where the platform leader can provide integrative infrastructure on which others can develop various applications. These IoT-business models facilitate the tracking of products in the entire supply chain, minimize stockouts, and implement just in time replenishment of the inventory. Thus, the supply chain management process in the IoT-enabled firms will become more collaborative where information about products and inventory is shared in real-time to increase the agility of the business.

\section{IoT and Customer Relationship Management}

The IoT-enabled smart objects will allow firms to acquire an extensive amount of product usage level data and consumer preferences directly from the end-users. Big data analytics of this information can potentially provide insights that the firms never had access to before. This creates new opportunities for firms in three major aspects of CRM: acquiring customers, enhancing customer experience, and retaining customers. Firms can use user preferences related information to launch personalized pricing and promotions to acquire new customers. Personalized usage data analytics and product performance data can be provided to the users to change their behavior and optimize product usage. Firms can provide proactive product services by monitoring product performance parameters in real-time. Such value-added services enhance the user experience and help in retaining customers and allow firms to implement a proactive CRM process.

IoT's application domains include a wide range of sectors, including smart cities, smart grid, smart household, and smart mobility (Borgia, 2014). The majority of business professionals around the world have considered IoT as one of the top technologies for investment in the next five years (Evans, 2018). Bandopadhyay \& Sen (2011) provide a list of industries including aerospace, automobile, manufacturing, healthcare, tourism, and insurance, where the implementation of IoT can improve the performance of the process, track items in the supply chain, and automate various operations. IoT is also considered to be one of the most promising technologies in the retail sector, and more than $70 \%$ of retailers surveyed worldwide are ready to adopt IoT to improve the overall customer experience, increase supply chain automation, and expand revenues (Columbus, 2017). In the last two decades, we have witnessed how the 


\section{Issues in Information Systems}

Volume 21, Issue 4, pp. 306-316, 2020

Internet and mobile computing have led the digital transformation of the firms. Likewise, the IoT can facilitate the next phase of the business transformation by extending the firm's PLM process, implementing the collaborative SCM, and enabling proactive CRM.

\section{METHODOLOGY}

The previous section summarizes the relevant literature in the context of the evolution of the electronic markets and IoT's role in improving the efficiency of the electronic markets by significantly improving the process of product life cycle management, supply chain management, and customer relationship management. In this section, based on the previous theoretical discussion, we analyze the IoT-enabled transformation of electronic markets and develop characteristics of the IoT-enabled electronic markets based on Bakos's characterization of the electronic markets functions. Our method of developing characteristics of the IoT-enabled electronic markets is based on the theoretical discussions in the previous two sections.

Just like their brick and mortar counterparts, electronic markets have three functions: matching participants, facilitating the transactions of the goods, services, information, and money, and providing an institutional infrastructure (Bakos, 1998). Unlike items sold at the traditional retail markets (both B\&M and electronic commerce), the items sold in electronic markets such as eBay and Amazon can be used or remanufactured as well. As discussed before, this has created challenges in the functioning of these markets. Electronic markets have been able to mitigate some of these challenges by integrating ICT tools. In the next few years, billions of smart objects (new, used, and remanufactured), generating zettabytes worth of data, will be traded on electronic markets. The IoT-enabled extended PLM, collaborative SCM, and proactive CRM features of these smart objects will transform electronic markets. The IoT will reduce search costs and information asymmetry further, enable efficient pricing discovery, and facilitate the effective matching of buyers and sellers because of the real-time data availability (transparency) of the listed items. The collaborative nature of the SCM process in IoT-enabled firms will engender better collaboration and coordination among producers of goods and services, participants of electronic markets, and logistics service providers. This will result in agile operations and facilitate efficient transactions. The data-driven rules and policies of the IoT will make the legal and regulatory framework of electronic marketplaces more automated.

\section{DISCUSSION}

The study of the contemporary literature in the fields of electronic markets and IoT indicates that the IoT will have a profound role in making three core business processes - product lifecycle management, supply chain management, and customer relationship management more efficient. Based on this, three primary characteristics of the IoT-enabled electronic markets have been derived. The IoT-enabled electronic markets will be more transparent for all stakeholders, will harness the power of effective collaboration among all supply chain partners in conducting various transactions, and will make the development and enforcement of the institutional infrastructure more automated.

\section{Characteristics of the IoT-Enabled Electronic Markets}

Table 1 summarizes three characteristics of IoT-enabled electronic markets, namely: transparent, collaborative, and automated, and how each of them affects the three main functions of electronic markets.

Transparent: Because of the extended PLM process of the smart objects, firms can keep track of the number of smart objects in the market, product performance data, and the usage pattern of the customers in real-time. As a significant number of items listed on electronic markets are used or remanufactured, this information is vital in identifying potential sellers, estimating inventory, assessing the quality of products, and learning buyer preferences more accurately. The ICT-based electronic markets use historical transactional data to provide analytics reports to help sellers optimize their listings. The IoT-enabled electronic markets can provide real-time data on demand patterns, market characteristics, and consumer preferences to help potential sellers to encourage listing of their products. For example, when a new version of an Apple iPhone or Nest thermostat is launched, electronic markets, in collaboration with the product manufacturers, can target selected owners to replace their products by trading in and subsequently listing them on electronic markets. Many of the current product listings in the secondary electronic markets consist of more qualitative and descriptive description with many details hidden in footprints. This makes it challenging for users 


\section{Issues in Information Systems}

Volume 21, Issue 4, pp. 306-316, 2020

to analyze the quality of the products. The IoT-enabled secondary electronic markets can effectively provide a standardized description based on real-time product performance data and hence reduce search costs associated with identifying the matching products.

Moreover, the buyers could be provided with personalized recommendations based on their actual usage pattern data. Better prediction of supply-demand and performance-driven standardized description of the used goods make price discovery more efficient in the IoT-enabled electronic markets. The reduction of information symmetry between sellers and buyers make the IoT-enabled electronic markets more transparent.

Collaborative: The learning of user preferences and acquiring product performance parameters require broader collaboration within a firm's supply chain, its industry, and even across related industries to share data and implement rules and policies. Through such collaborative ecosystems, manufacturing firms can keep track of their smart products in the entire supply chain, including retailers' shelves, consumers' homes, and even secondary electronic markets' listings. Retailers can manage their inventories more effectively by tracking them from the shelves to minimize stockouts and access inventories. IoT can increase the visibility of items in the supply chain in real-time and facilitate agile SCM for electronic markets. IoT-enabled drones can be used for specialized deliveries. Many electronic markets have their B\&M storefronts. Amazon, for example, has cashierless stores wherein buyers' picking off an item can be tracked using RFID sensors and cameras to process payments automatically.

The product descriptions and details on electronic markets are usually entered by, and in many instances, they are inconsistent, lengthy, and qualitative. In the IoT-enabled electronic markets, product description data can come directly from manufacturers. Moreover, in the secondary market transactions, the product quality and performancerelated data can directly be obtained from the seller's smart objects, which helps in removing any inconsistencies and misrepresentations. More standardized and data-driven product listings help in establishing trust in the electronic markets.

Automated: Currently, the regulatory and legal framework for the institutional infrastructure requires manual efforts from the users. The users can report an electronic marketplace about the listings violating intellectual property violations or selling counterfeit products. The users can also register complaints against the other trade participants for any contractual breaches regarding non-receipt of the correct item or payments. Such disputes discourage users from participating in electronic markets. The extended PLM and collaborative SCM features of the IoT-enabled electronic markets allow automatic tracking of items. They even make it possible to analyze their performance parameters and automate the identification and resolution of any contractual violations. Such automated enforcement of rules and controls encourage more users to engage in electronic market trades.

Listing of the counterfeit products is rampant and a significant problem for electronic markets as it leads to trust issues, disputes, and eventually discourage buyers from engaging in a trade. Companies, including Mercedes-Benz and Birkenstock, have filed lawsuits or pulled products from Amazon, citing counterfeiting and unauthorized selling (Alaimo, 2018). The IoT-enabled PLM process enables verifying the details of the smart objects throughout its lifecycle, and electronic markets can automate the detection and removal of products violating intellectual property rights and counterfeits. 
Table 1. Electronic market (EM) functions (Bakos, 1998), characteristics of IoT-enabled EMs and How IoT transforms the basic EM functions

\begin{tabular}{|c|c|c|c|}
\hline \multicolumn{2}{|c|}{ EM Functions* } & $\begin{array}{c}\text { Characteristics } \\
\text { of IoT-Enabled } \\
\text { EMs }\end{array}$ & IoT's Transformation of Basic EM Functions \\
\hline \multirow{3}{*}{$\begin{array}{l}\text { Matching of } \\
\text { Participants }\end{array}$} & Product Offerings & \multirow{3}{*}{ Transparent } & $\begin{array}{l}\text { Better accuracy in supply-demand prediction; real-time analytics } \\
\text { report of sellers and user preferences }\end{array}$ \\
\hline & $\begin{array}{l}\text { Search Costs } \\
\text { (product, } \\
\text { participants) }\end{array}$ & & $\begin{array}{l}\text { Standardized quantitative item descriptions based on product } \\
\text { performance parameters; personalized recommendations based on } \\
\text { user preferences }\end{array}$ \\
\hline & Price discovery & & Efficient price discovery based on accurate supply and demand \\
\hline \multirow{2}{*}{$\begin{array}{l}\text { Facilitating } \\
\text { Transactions }\end{array}$} & $\begin{array}{l}\text { Logistics and } \\
\text { Settlement }\end{array}$ & \multirow{2}{*}{ Collaborative } & $\begin{array}{l}\text { Agile SCM, inventory management, item visibility, IoT drone } \\
\text { delivery, RFID in-store payments (Amazon cashless stores) }\end{array}$ \\
\hline & Trust & & $\begin{array}{l}\text { Verifiable standardized quantitative item descriptions based on } \\
\text { product performance parameters; verifiable deliveries }\end{array}$ \\
\hline \multirow{3}{*}{$\begin{array}{l}\text { Institutional } \\
\text { Infrastructure }\end{array}$} & $\begin{array}{l}\text { Dispute } \\
\text { Resolution }\end{array}$ & \multirow{3}{*}{ Automated } & $\begin{array}{l}\text { Automatic identification of non-deliveries with better item } \\
\text { visibility, verifiable product performance parameters }\end{array}$ \\
\hline & $\begin{array}{l}\text { Rules, Controls, } \\
\text { Enforcement }\end{array}$ & & $\begin{array}{l}\text { Standardized direct descriptions from manufacturers and smart } \\
\text { objects for product listings; automated rules for any exceptions }\end{array}$ \\
\hline & $\begin{array}{l}\text { IP, Counterfeit } \\
\text { Protection }\end{array}$ & & $\begin{array}{l}\text { Verifiable authenticity of an item; automatic removal of listings } \\
\text { in non-compliance }\end{array}$ \\
\hline
\end{tabular}

\section{Challenges in electronic markets' transformation}

As table 1 summarizes, transparent, automated, and collaborative IoT-enabled electronic markets significantly improve the functional efficiency of their participants. However, before reaching its full IoT-enabled potential, electronic markets will have to go through significant challenges related to security and privacy, big data and networks, and interoperability.

The networked IoT devices are connected to the firm's servers and transfer data daily. Any of these devices can potentially be breached and used to access the firm's network through the backdoor entry. While data security has become of paramount importance for traditional computing devices, the same level of rigorous security standards is not established for the IoT devices. IoT devices can be used collectively for carrying out distributed denial of service attacks (DDoS). Moreover, IoT devices capture, store, process, and communicate sensitive data, including healthcare and financial information. Such information is continuously obtained from the users to learn their preferences and usage characteristics. IoT has made it possible for smart TVs and speakers to monitor household conversations, smart refrigerators to monitor grocery shopping habits, smartwatches to track daily movements and sleep, and smart cars to check the operators' driving habits. The regulatory and policy framework on how these data are collected, stored, disseminated, and used is not clear yet. It is critical that before unleashing the full power of the IoT-enabled electronic markets, security technology and policy for the IoT devices is evolved, and a clear consent-driven privacy policy framework is established.

Big Data: The IoT devices can capture, store, and transfer a large volume of data continuously. Moreover, this data comes in real-time and can contain multimedia features, including audio, video, text, and pictures. Users of a popular activity tracker device Fitbit have reported that as much as 3.5 GB of data was collected and used by the activity tracker just in a few days (Lamkin, 2018). This data included GPS coordinates, sleep patterns, movements, exercises, and even heartbeats. Collecting, transferring, storing, analyzing, and acting on such big data is one of the biggest challenges that the IoT-enabled firms must face. Prior scholars have suggested the use of edge computing wherein the bulk of the computation and data processing tasks happen at the edge of the network (i.e., at the smart object level), reducing the need for big data transfer (Stojkoska \& Trivodaliev, 2017). The development of the standardized big data 


\section{Issues in Information Systems}

Volume 21, Issue 4, pp. 306-316, 2020

infrastructure is a pre-condition for implementing the extension of the PLM process and proactiveness in the CRM process for the IoT-enabled businesses and electronic markets.

Interoperability: The ecosystem of the IoT-enabled firms goes beyond the firm's boundary, within or even across its industry. To learn about user preferences, data from the different smart objects must be collected, stored, integrated, and analyzed in a central system. This may require firms with competing priorities to collaborate and share data. Achievement of the full interoperability between different devices and applications is expected. Interoperability not only needs technological integration but also requires policy formulations assuring access controls and security as well as the privacy of the data.

Once electronic markets address these challenges of security and privacy, big data analytics and networks, and interoperability, they will be transformed into transparent, collaborative, and automated markets. The next generation of IoT-enabled electronic markets will continue integrating advances in technology, including artificial intelligence, to automate various operations.

\section{CONCLUSIONS}

The evolution of the electronic markets has clearly shown the role of ICT tools in increasing market efficiency. The popular ICT tools such as parametric search, reputation feedback mechanism, reviews and ratings, personalization, and recommender systems have played a significant role in reducing information asymmetry, price dispersion, trade risks, and uncertainties. The recent development of the IoT-led technological platform has enabled the transformation of the core business processes of product lifecycle management, supply chain management, and customer relationship management. In this paper, the IoT-enabled electronic markets are analyzed based on the theoretical developments in the fields of the electronic markets and IoT. The paper concludes that the IoT-enabled electronic markets will further improve the efficiency of the electronic markets by making them more transparent, collaborative, and automated. The paper discusses three significant challenges that can affect the transformation of the electronic markets. They are big data analytics, interoperability, and security/privacy.

The analysis in this paper is based on contemporary theory and practical developments in the areas of electronic markets and IoTs. The research does not include any empirical analysis suggesting the improvement in the market efficiency based on IoT-enabled transparency, collaboration, and automation in the electronic markets. Once electronic markets start integrating IoT into their business models, future research opportunities exist in the field of the empirical analysis of the IoT-enabled electronic markets.

\section{REFERENCES}

Ackoff, R. L. (1967). Management misinformation systems. Management Science, 14(4), B-147.

Alaimo, D. (2018, June 26). Amazon, eBay, join the effort to combat counterfeits. Retrieved from http://www.retaildive.com/news/amazon-ebay-join-effort-to-combat-counterfeits/526527/.

Atzori, L., Iera, A., \& Morabito, G. (2010). The Internet of things: A survey. Computer networks, 54(15), 2787-2805.

Ba, S., \& Pavlou, P. A. (2002). Evidence of the effect of trust building technology in electronic markets: Price premiums and buyer behavior. MIS quarterly, 243-268.

Bakos, J. Y. (1997). Reducing buyer search costs: Implications for electronic marketplaces. Management Science, 43(12), 1676-1692.

Bakos, Y. (1998). The emerging role of electronic marketplaces on the Internet. Communications of the ACM, 41(8), 35-42. 


\section{Issues in Information Systems}

Volume 21, Issue 4, pp. 306-316, 2020

Bandyopadhyay, D., \& Sen, J. (2011). Internet of things: Applications and challenges in technology and standardization. Wireless Personal Communications, 58(1), 49-69.

Benson, A., Sojourner, A., \& Umyarov, A. (2020). Can reputation discipline the gig economy? Experimental evidence from an online labor market. Management Science, 66(5), 1802-1825.

Bauer, I., Zavolokina, L., \& Schwabe, G. (2019). Is there a market for trusted car data?. Electronic Markets, $1-15$.

Bolton, G. E., Kusterer, D. J., \& Mans, J. (2019). Inflated reputations: Uncertainty, leniency, and moral wiggle room in trader feedback systems. Management Science, 65(11), 5371-5391.

Borgia, E. (2014). The Internet of Things vision: Key features, applications, and open issues. Computer Communications, 54, 1-31.

Baye, M. R., Morgan, J., \& Scholten, P. (2006). Information, search, and price dispersion. Handbook on economics and information systems, 1, 323-375.

Bucherer, E., \& Uckelmann, D. (2011). Business models for the Internet of things. In Architecting the internet of things (pp. 253-277). Springer, Berlin, Heidelberg.

Chen, P. Y., \& Hitt, L. M. (2002). Measuring switching costs and the determinants of customer retention in Internetenabled businesses: A study of the online brokerage industry. Information systems Research, 13(3), 255-274.

Clay, K., Krishnan, R., Wolff, E., \& Fernandes, D. (2002). Retail strategies on the web: Price and non-price competition in the online book industry. The Journal of Industrial Economics, 50(3), 351-367.

Columbus, L. (2017, March 19). Internet Of Things Will Revolutionize Retail. Retrieved from http://www.forbes.com/sites/louiscolumbus/2017/03/19/internet-of-things-will-revolutionizeretail/\#3aa8bbfa5e58

Da Xu, L., He, W., \& Li, S. (2014). Internet of things in industries: A survey. IEEE Transactions on industrial informatics, 10(4), 2233-2243.

Danziger, P. N. (2018, April 28). Thinking Of Selling On Amazon Marketplace? Here Are The Pros And Cons. Retrieved from http://www.forbes.com/sites/pamdanziger/2018/04/27/pros-and-cons-of-amazon-marketplace-forsmall-and-mid-sized-businesses/\#306140746867

Dohr, A., Modre-Opsrian, R., Drobics, M., Hayn, D., \& Schreier, G. (2010, April). The Internet of things for ambient assisted living. In Information technology: new generations (ITNG), 2010 seventh international conference on (pp. 804-809). IEEE.

Evans, M. (2018, May 31). IoT Will Have The Most Impact On Business In The Next Five Years, Survey Says. Retrieved from http://www.forbes.com/sites/michelleevans1/2018/05/31/iot-will-have-the-most-impact-onbusiness-in-the-next-five-years-survey-says/\#7d6fe8015a3d

Grover, V., Lim, J., \& Ayyagari, R. (2006). The dark side of information and market efficiency in emarkets. Decision

Sciences, 37(3), 297-324.

Hanna, N. K. (2003). Why National Strategies are needed for ICT-enabled Development. World Bank Staff Paper. Washington, DC: World Bank. 
Hiltz, S. R., \& Turoff, M. (1985). Structuring computer-mediated communication systems to avoid information overload. Communications of the ACM, 28(7), 680-689.

Keller, K. L., \& Staelin, R. (1987). Effects of quality and quantity of information on decision effectiveness. Journal of consumer research, 14(2), 200-213.

Kanellos, M. (2016, March 09). 152,000 Smart Devices Every Minute In 2025: IDC Outlines the Future of Smart Things. Retrieved from http://www.forbes.com/sites/michaelkanellos/2016/03/03/152000-smart-devices-everyminute-in-2025-idc-outlines-the-future-of-smart-things/\#315019c64b63

Kortuem, G., Kawsar, F., Sundramoorthy, V., \& Fitton, D. (2010). Smart objects as building blocks for the Internet of things. IEEE Internet Computing, 14(1), 44-51.

Lamkin, P. (2018, July 12). Fitbit Promises Fix for Data Drain Problem. Retrieved from https://www.forbes.com/sites/paullamkin/2018/07/11/fitbit-promises-fix-for-data-leak-problem/\#1eb1321340dd

Lee, B. K., \& Lee, W. N. (2004). The effect of information overload on consumer choice quality in an online environment. Psychology \& Marketing, 21(3), 159-183.

Lee, I. H., \& Mason, R. (2001). Market structure in congestible markets. European Economic Review, 45(4-6), 809818.

Leminen, S., Rajahonka, M., Westerlund, M., \& Wendelin, R. (2018). The future of the Internet of Things: toward heterarchical ecosystems and service business models. Journal of Business \& Industrial Marketing, 33(6), 749767.

Li, S., Da Xu, L., \& Zhao, S. (2015). The Internet of things: a survey. Information Systems Frontiers, 17(2), 243-259.

Lyytinen, K., \& King, J. L. (2006). Standard making: a critical research frontier for information systems research. Mis Quarterly, 30, 405-411.

Malhotra, N. K. (1982). Information load and consumer decision making. Journal of consumer research, 8(4), 419430.

Malone, T. W., Yates, J., \& Benjamin, R. I. (1987). Electronic markets and electronic hierarchies. Communications of the ACM, 30(6), 484-497.

Pathak, B., Garfinkel, R., Gopal, R. D., Venkatesan, R., \& Yin, F. (2010). An empirical analysis of the impact of recommender systems on sales. Journal of Management Information Systems, 27(2), 159-188.

Pontiggia, A., \& Virili, F. (2010). Network effects in technology acceptance: Laboratory experimental evidence. International Journal of Information Management, 30(1), 68-77.

Resnick, P., \& Zeckhauser, R. (2002). Trust among strangers in Internet transactions: Empirical analysis of eBay's reputation system. In The Economics of the Internet and E-commerce (pp. 127-157). Emerald Group Publishing Limited.

Sicari, S., Rizzardi, A., Grieco, L. A., \& Coen-Porisini, A. (2015). Security, privacy, and trust in the Internet of Things: The road ahead. Computer networks, 76, 146-164.

Smith, M. D., \& Brynjolfsson, E. (2001). Consumer decision-making at an Internet shopbot Brand still matters. The Journal of Industrial Economics, 49(4), 541-558. 


\section{Issues in Information Systems}

Volume 21, Issue 4, pp. 306-316, 2020

Soh, C., Markus, M. L., \& Goh, K. H. (2006). Electronic marketplaces and price transparency: strategy, information technology, and success. MIS quarterly, 705-723.

Stankovic, J. A. (2014). Research directions for the Internet of things. IEEE Internet of Things Journal, 1 (1), 3-9.

Stojkoska, B. L. R., \& Trivodaliev, K. V. (2017). A review of the Internet of Things for the smart home: Challenges and solutions. Journal of Cleaner Production, 140, 1454-1464.

Swan, J. E., \& Nolan, J. J. (1985). Gaining customer trust: a conceptual guide for the salesperson. Journal of Personal Selling \& Sales Management, 5(2), 39-48.

Varadarajan, P. R., \& Yadav, M. S. (2002). Marketing strategy and the internet: an organizing framework. Journal of the Academy of Marketing Science, 30(4), 296-312.

Welbourne, E., Battle, L., Cole, G., Gould, K., Rector, K., Raymer, S., \& Borriello, G. (2009). Building the Internet of things using RFID: the RFID ecosystem experience. IEEE Internet Computing, 13(3).

Westerlund, M., Leminen, S., \& Rajahonka, M. (2014). Designing business models for the Internet of things.

Weiller, C., \& Neely, A. (2013). Business model design in an ecosystem context. University of Cambridge, Cambridge Service Alliance.

Zanella, A., Bui, N., Castellani, A., Vangelista, L., \& Zorzi, M. (2014). Internet of things for smart cities. IEEE Internet of Things Journal, 1(1), 22-32.

Zhang, Y., \& Wen, J. (2017). The IoT electric business model: Using blockchain technology for the Internet of things. Peer-to-Peer Networking and Applications, 10(4), 983-994. 